\title{
On the Decrease of Arctic Sea Ice Volume
}

\author{
Michael Hilmer and Peter Lemke \\ Institut für Meereskunde an der Universität Kiel, Germany
}

\begin{abstract}
The decrease of Arctic sea ice volume is investigated using a dynamic-thermodynamic sea ice model. The model was forced with NCEP/NCAR reanalysis winds and surface air temperatures in a hindcast simulation of the period 1958-1998. The simulation reveals pronounced decadal variability (10-12 years) along with a significant linear negative trend of total Arctic sea ice volume which amounts to $-4 \% /$ decade. The decrease is apparent throughout the annual cycle with largest amplitudes from September to December. Regionally the strongest thinning of ice thickness occurs in the East Siberian Sea with magnitudes up to $-30 \mathrm{~cm} /$ decade. The simulation also reveals some positive trends in the Baffin Bay/Labrador Sea and north of the Canadian Archipelago.
\end{abstract}

\section{Introduction}

Climate model projections of a future climate change due to increased greenhouse gas concentrations show a maximum annual mean warming near the surface in the high northern latitudes [Houghton, 1996]. This warming is aligned with a retreat of sea ice. Sensitivity experiments with a sophisticated sea ice model [Fischer and Lemke, 1994] have revealed that the sea ice cover is most strongly affected by the surface air temperature (SAT) and the surface wind field. Other forcing parameters play a minor role. Hence it can be expected that changes in these forcing quantities leave their imprint on the sea ice cover. From observations there is evidence that Northern Hemisphere SAT has risen by about half a degree within the 20th century [e.g. Chapman and Walsh, 1993; Jones, 1994]. Changes of the wind field in the Arctic towards a more cyclonic circulation are reported by Walsh et al. [1996], who describe a decrease of central Arctic sea level pressure (SLP) over the last two decades being most pronounced since the late 1980s. An increasing number of observational studies, based on satellite derived ice concentrations, report a reduction of Arctic sea ice during the last two decades [Bjørgo et al., 1997; Cavalieri et al., 1997]. In recent papers Parkinson et al. [1999] and Gloersen et al. [1999] report a statistically significant negative trend of $-2.8 \% /$ decade in Arctic sea ice extent and sea ice area derived from an 18-years satellite based dataset (1978-1996). Moreover, Johanessen et al. [1999] found from satellite observations a reduction of the winter (NovemberMarch) multiyear ice area of $-7 \% /$ decade, thus indicating a change of the nature of the perennial ice pack. Rothrock et al. [1999] analysed sea ice draft data acquired on submarine cruises for the periods 1993-1997 and 1958-1976. They found, at least during the summer season, a decrease of the

Copyright 2000 by the American Geophysical Union.

Paper number 2000GL01 1403

0094-8276/00/2000GL011403\$05.00 mean ice draft by about $1.3 \mathrm{~m}$ in most of the deep water portion of the Arctic ocean.

However, for estimating long-term changes of large scale sea ice quantities observations suffer from the relatively shortness of the available time series and partly from a small spatial coverage. In this paper we analyse a hindcast experiment with a dynamic-thermodynamic sea ice model forced with atmospheric data from 1958-1998 to study long-term changes of the Arctic sea ice volume.

\section{Model Description and Experimental Design}

An optimized dynamic-thermodynamic sea ice model [Lemke et al., 1997; Harder et al., 1998] with viscousplastic rheology [Hibler, 1979] and seven thermodynamic icethickness categories is used. The model domain spans the entire Arctic ocean and extents southward to about $55^{\circ} \mathrm{N}$ in the North Atlantic region (see Fig. 4). The model equations are solved on a rotated, spherical grid with a horizontal resolution of $1^{\circ} \times 1^{\circ}$ using a daily time step. Daily fields of $2 \mathrm{~m}$ surface air temperature and $10 \mathrm{~m}$-surface winds taken from the National Center of Environmental Prediction/National Center of Atmospheric Research (NCEP/NCAR) reanalyis project [Kalnay et al., 1996] for the period 1958-1998 were used to force the model. Forcing fields of precipitation, total cloud coverage and humidity were derived from the European Centre of Medium Range Weather Forecasting (ECMWF) 15-year reanalysis project (ERA-15) [Gibson et al., 1997] and were prescribed as a mean annual cycle. The mean annual cycle of oceanic heat flux and the mean ocean currents were derived from an integration of a coupled sea ice-ocean model [ $C$. Koeberle, AWI Bremerhaven, Germany, personal communication].

For the spin-up integration, starting from an ice-free ocean, the model was repeatedly forced with a standard forcing to reach a near equilibrium state. Instead of using a mean annual cycle of SAT and winds, we used the 1986 data of NCEP/NCAR $2 m$-surface air temperature and $10 \mathrm{~m}$-surface winds as a standard forcing. This avoids problems which occur when using averaged wind vectors. The year 1986 was choosen, because it represents a 'normal' year within the 41-year period of the NCEP/NCAR dataset. That is, the principal components of the first three empirical orthogonal functions of anomalous monthly means of SAT and SLP have a near zero-crossing at this time. A 41-year control integration using the standard forcing reveals that even after a spin-up integration for $\mathbf{5 0 0}$ years there remains still a slight increase of the modelled total sea ice volume of of $0.01 \% /$ decade.

To estimate the influence of the initial conditions on the simulation results, an additional 41-year integration was performed. Here, the model was repeatedly forced with the atmospheric data from 1958, the first year of the 


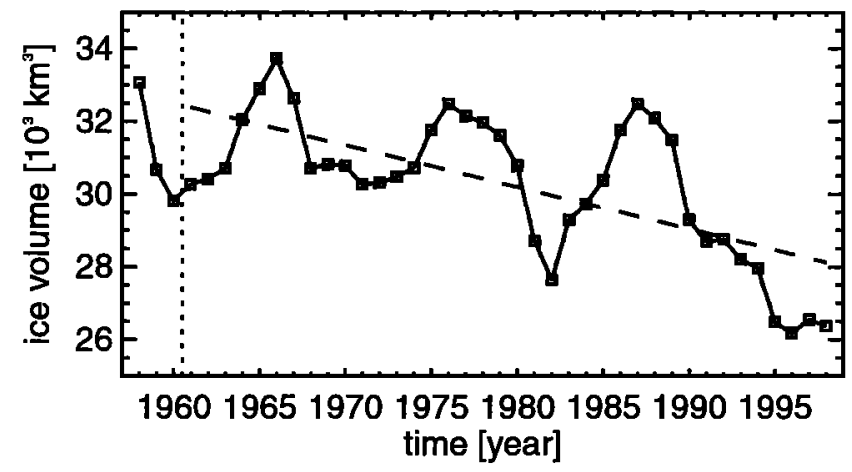

Figure 1. Temporal change of total Arctic sea ice volume. Annual means (solid with squares) and linear least squares fit (dashed) of total Arctic sea ice volume $\left(10^{3} \mathrm{~km}^{3}\right)$ are shown. Estimates are influenced by the initial conditions during the first three years (vertical dotted line).

NCEP/NCAR dataset. From an analysis of the annual mean ice volume time series of this simulation it was found that the difference to the ice volume at the end of this integration has an e-folding time of roughly three years. That is, the annual mean ice volume of the first three years of the simulation is significantly affected by the initial field. Therefore, the first three years were excluded from the subsequent analysis.

\section{Simulated Variability and Trends}

The simulated mean state is very similiar to that described in Hilmer et al. [1998] (their Fig. 1). Relatively small ice thicknesses occur in the eastern Arctic (1-2 $m$ ) increasing westward up to 5-6 $m$ in the region north of Greenland and Ellesmere Island. At the North Pole, the model predicts ice thicknesses of $3-4 \mathrm{~m}$.

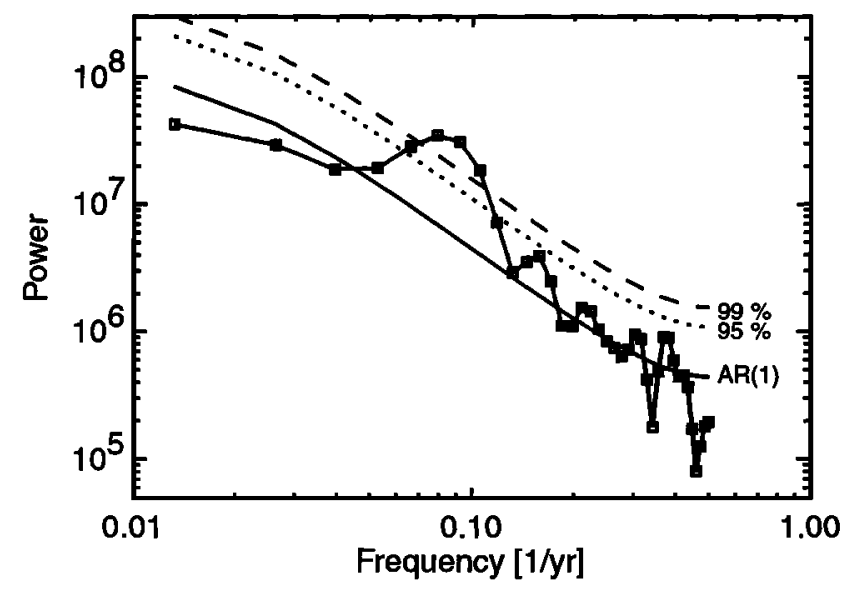

Figure 2. Power spectrum of modelled total Arctic sea ice volume for the period 1961-1998 (solid line with squares). The spectrum of a first order auto-regressive process is underlined (solid) along with the $95 \%$-(dotted) and $99 \%$-(dashed) confidence levels at which the local null-hypothesis of 'red noise' can be rejected. The probability for the just-by-chance occurence of three or more spectral peaks above the local $99 \%$-confidence level is $2.3 \%$. This global test is based on 10000 realizations of the 'red noise' null hypothesis. The spectra were estimated by taking the Fourier transform of the autocovariance function using a Bartlett-window with a maximum lag of 19 years.

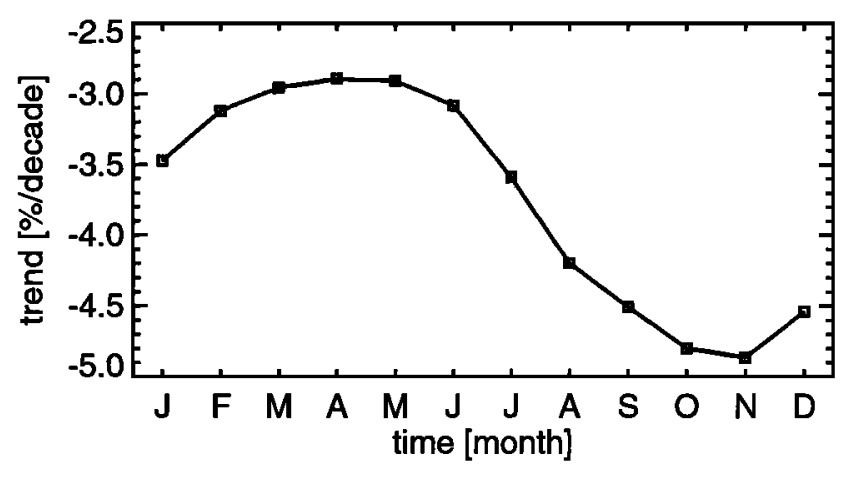

Figure 3. Annual cycle of the long-term trends of sea ice volume (\%) relative to the overall mean value. Linear regressions of the monthly mean anomalies from the mean annual cycle of sea ice volume were calculated. Again, only data for the period 19611998 were used.

The total sea ice volume is defined as the sum over the ice thicknesses at each grid point multiplied by their grid cell area. The long-term mean value of the total sea ice volume in the model domain amounts to $30.2 \cdot 10^{3} \mathrm{~km}^{3}$ within the period 1961-1998. However, the annual means (Fig. 1) show large variability about this mean state with a standard deviation of $1.9 \cdot 10^{3} \mathrm{~km}^{3}$, that is, $6 \%$ of the long-term mean. The simulation yields three relative maxima of ice volume, which occured around the years 1966, 1977 and 1987. Although the time series is rather short, a spectral analysis of the annual mean time series (1961-1998) reveals a highly significant peak at periods of 10-12 years (Fig. 2). Beyond these decadal fluctuations, there is a linear decrease of Arctic sea ice volume of $-4 \%$ /decade (relative to the overall mean), which is statistically significant at the $95 \%$ confidence level (for details concerning the test see legend in Fig. 4). The trend was estimated by applying linear least squares regression to the annual mean values for the period 1961-1998.

The negative trend shows a pronounced seasonality; the largest decrease occurs in autumn with magnitudes up to $-4.8 \% /$ decade (relative to the overall long-term mean value), whereas the smallest trends $(-2.8 \% /$ decade $)$ are found in spring (Fig. 3). This seasonal dependence cannot be explained by the seasonal cycle of the SAT trends alone, but is obviously a complex nonlinear response to thermodynamic and dynamic forcing. Due to the nonlinearity of the heat conduction equation [Semtner, 1976] thin ice is more sensible to temperature variations than thick ice [see also Fischer and Lemke, 1994]. For the model domain, the SAT forcing shows largest increases in spring, whereas nearly no trend is apparent during the months July to September (not shown). However, during the melt season the SAT is locked to the melting temperature of snow and ice when sea ice is present. Smith [1998] has shown from both passive microwave data and NCEP/NCAR reanalysis SATs that the length of the melt season has increased by $8 \%$ per decade for the period 1979-1996 and that this increase can be attributed mainly to a positive trend in the freeze-up date usually occuring in early September.

Regionally, the ice thickness trends reflect roughly thd inverse of the SAT trend pattern. Arctic SAT trends are described, e.g., by Chapman and Walsh [1993] and Serreze et al. [2000]. The model shows a thinning of sea ice in 


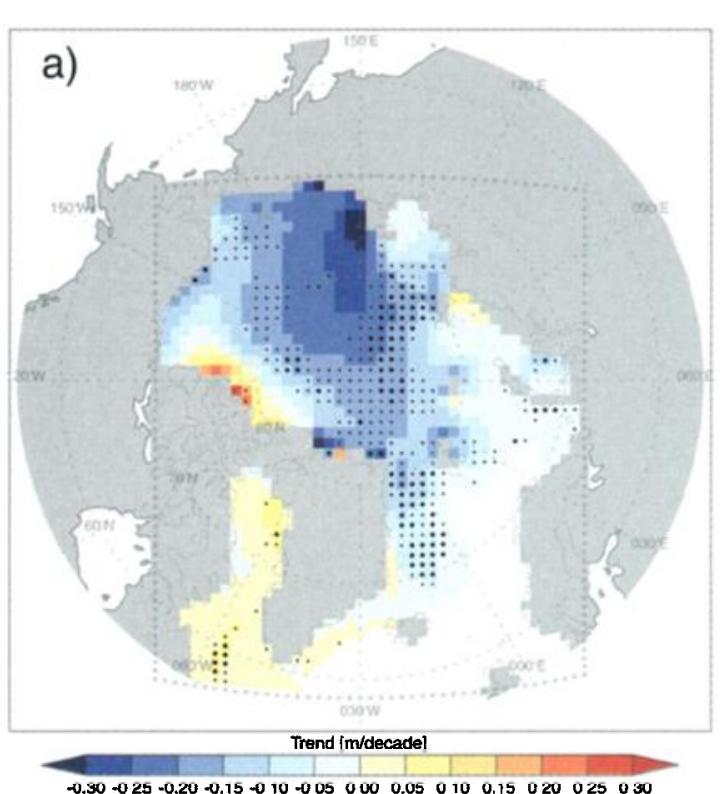

$-0.30-0.25-0.20-0.15-010-0050000.050100 .15020025030$

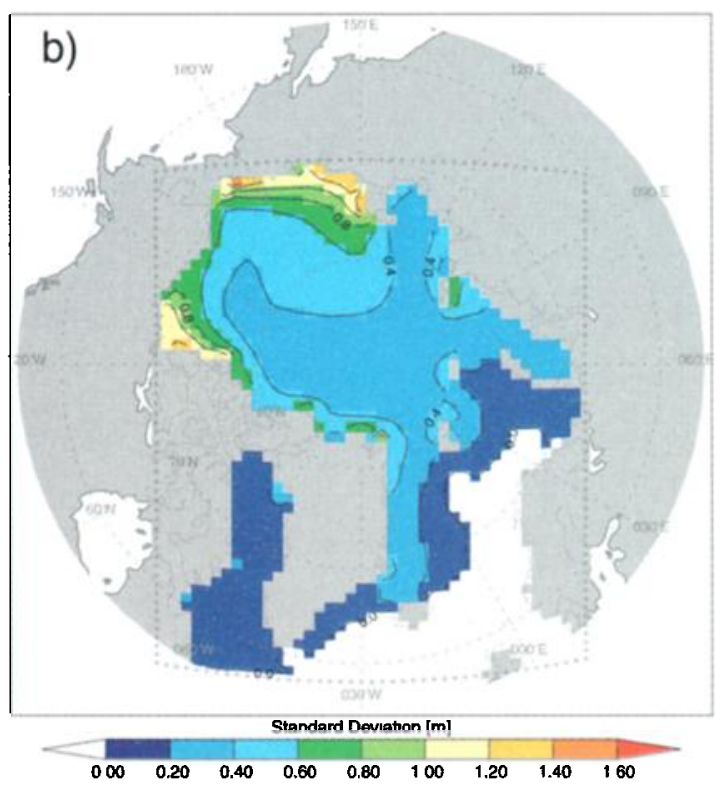

Figure 4. Long-term trends and interannual variability of simulated Arctic ice thickness from 1961 to 1998. (a) The slopes of the linear regressions of annual mean ice thicknesses ( $m /$ decade) for each grid point are shown. The significance of the trends was tested against the null-hypotheses 'no negative trend' or 'no positive trend', respectively, using a two-sided Mann-Kendall-test. Prior to the test the time series were prewhitened. This avoids a liberal test due to serial correlation [von Storch and Zwiers, 1999]. Statistically significant values on the $90 \%$-(95\%-)confidence level are indicated by small (large) dots. (b) The standard deviations of annual mean ice thicknesses $(m)$ for each grid point is shown. The crosses in each plot mark the model domain.

most parts of the Arctic ocean and an increase in the Baffin Bay/Labrador Sea region (Fig. 4a). Within the Arctic ocean, the strongest thinning occurs in a region extending from the North Pole to the East Siberian Sea with magnitudes up to $-30 \mathrm{~cm} /$ decade east of the New Siberian Islands. Sensitivity simulations (not shown) including interannual and longer-term variability of either SAT or the wind field only have revealed that this region of maximum thinning can mainly be attributed to changes of SAT rather than to circulation changes which come along with the SLP decrease. Moderate trends are found in the region from the North Pole to Fram Strait with magnitudes between $-15 \mathrm{~cm} /$ decade and $-20 \mathrm{~cm} /$ decade.

The thinnning of sea ice in the region upstream of Fram Strait may influence the long-term characteristics of the ice volume export out of the Arctic ocean. This efflux is determined by both, the thickness of the ice entering Fram Strait and its southerly drift speed component. Whereas the ice thickness has decreased over the last four decades the southward component of ice drift speed has increased (not shown). As a result of these opposing trends there is no significant long-term change of the modelled ice volume export through Fram Strait (slight decrease of $0.2 \% /$ decade relative to the long-term mean of $0.085 S v$ ).

In the Beaufort Sea, the negative trends are rather small and trends are positive north of the Canadian Archipelago. These positive trends are presumably caused by dynamical effects, because the SAT forcing exhibits a positive trend in this region too. Due to a decrease of SLP the Beaufort Gyre has weakened and, as a consequence, less ice was advected out of this region. An increase of ice thickness in this region is consistent with a positive trend in sea ice concentration as reported by Gloersen et al. [1999].

The statistical significance of trends depends (besides the length of the sample) on the signal-to-noise ratio between the trend and higher frequency fluctuations of the considered time series. Figure $4 \mathrm{~b}$ shows the spatial structure of the interannual "noise" of simulated ice thickness. Largest amplitudes of the standard deviations are found in the East Siberian Sea and in the Beaufort Sea with magnitudes up to $1.2 \mathrm{~m}$. Except for the ice edges, where the long-term mean ice thicknesses are small, a relative minimum of interannual ice thickness variability appears in the region around the North Pole with standard deviations of $0.2-0.4 \mathrm{~m}$. Thus, even moderate trends in this area are almost everywhere significant (Fig. 4a).

\section{Discussion and Conclusions}

Overall, the simulated trend pattern resulting from our simulation agrees fairly well with the pattern of ice draft changes based on submarine data between the periods 19931997 and 1958-1976, described by Rothrock et al. [1999]. By taking into account the decadal variations of the modelled ice volume we suppose that the long-term change of ice volume derived from ice draft data for these two periods may be overestimated. Moreover, data from the end of the melt season were analysed-the time of the year when the simulation yields enhanced decrease of sea ice volume (Fig. 3). Nevertheless, the reduction of the modelled total sea ice volume of $-15 \%$ over the last 38 years represents an undoubtedly strong climate signal. As discussed by Rothrock et al. [1999] observational data of the 1990s show a continuation of the thinning. Deviding the modelled ice volume time series into three partly overlapping 12-year periods (1964-1975, 1976$1986,1987-1998)$ it turns out that the decrease within the last twelve years was three to six times larger than within the previous periods.

In summary, a hindcast experiment with a dynamicthermodynamic sea ice model forced with realistically atmo- 
spheric data reveals a net reduction of Arctic sea ice volume of $-4 \% /$ decade. Consistent with observational studies the largest thinning occurs in the eastern Arctic. Because the ice export out of the Arctic ocean did not increased, the net thinning of Arctic sea ice can mainly be explained by less freezing during autumn and early winter.

It is noteworthy, that the sea ice model can only respond to changes which arise from the SAT and wind field forcing. The simulation does not include possible contributions from other forcing parameters to the changes of sea ice like, for example, the hydrological cycle (e.g. changes in precipitation, evaporation, river discharges, and cloudiness) or oceanic processes (e.g. changes of oceanic heat flux or current systems) on interannual or longer time scales.

Acknowledgments. We thank C. Eden and T. Jung for helpful comments; R. Gerdes and C. Koeberle for providing the oceanic forcing. The ERA-15 data were kindly provided by the Deutsches Klimarechenzentrum Hamburg. NCEP/NCAR reanalysis data were provided through the NOAA Climate Diagnostics Center (http://www.cdc.noaa.gov). This is a contribution of the Sonderforschungsbereich 460 "Dynamics of Thermohaline Circulation Variability" at the University of Kiel (http://www.ifm.unikiel.de/general/sfb460-e.html) supported by the German Science Foundation.

\section{References}

Bjørgo, E., O.M. Johanessen, and M.W. Miles, Analysis of merged SMMR-SSM/I time series of Arctic and Antarctic sea ice parameters 1978-1995. Geophys. Res. Lett., 24(4), 413$416,1997$.

Cavalieri, D.J., C.L. Parkinson, J.C. Comiso, and H.J. Zwally, Observed hemispheric asymmetry in global sea ice changes. Science, 278, 1104-1106, 1997.

Chapman, W.L. and J.E. Walsh, Recent variations of sea ice and air temperature in high latitudes. Bull. Amer. Meteor. Soc., $74(1), 33-47,1993$.

Fischer, H. and P. Lemke, On the required accuracy of atmospheric forcing fields for driving dynamic-thermodynamic sea ice models. In: The Polar Oceans and their role in shaping the global environment, Geophys. Monogr. Ser., vol. 85, AGU, Washington D. C., 373-381, 1994.

Gibson, P., J.K. Kallberg, S. Uppala, A. Hernandez, A. Nomura, and E. Serrano, ECMWF re-analysis, project report series: 1. ERA description. Europe an Centre for Medium-Range Weather Forecasting, Reading UK, p. 72, 1997.

Gloersen, P., C.L. Parkinson, D.J. Cavalieri, J.C. Comiso, and H.J. Zwally, Spatial distribution of trends and seasonality in the hemispheric sea ice covers: 1978-1996. J. Geophys. Res., 104(C9), 20,827-20,835, 1999.
Harder, M., H. Lemke, and M. Hilmer, Simulation of sea ice transport through Fram Strait: Natural variability and sensitivity to forcing. J. Geophys. Res., 103(C3), 5595-5606, 1998.

Hibler, W. D., A dynamic-thermodynamic sea ice model. J. Phys. Oceanogr., 9(4), 815-846, 1979.

Hilmer, M., M. Harder, and P. Lemke, Sea ice transport: A highly variable link between Arctic and North Atlantic. Geophys. Res. Lett., 25(17), 3359-3362, 1998.

Houghton, J. T., ed., Climate Change 1995: The Science of Climate Change. Cambridge Univ. Press, ISBN 0-521-56436-0, 1996.

Johanessen, O. M., E.V. Shalina, and M.W. Miles, Satellite evidence for an Arctic sea ice cover in transformation. Science, $286,1937-1939,1999$.

Jones, P. D., Hemispheric surface air temperature variations: a reanalysis and an update to 1993 . J. Climate, 7, 1794-1802, 1994.

Kalnay, E., et al., The NCEP/NCAR 40-year reanalysis project. Bull. Amer. Meteor. Soc., 77(3), 437-470, 1996.

Lemke, P., W.D. Hibler, G. Flato, M. Harder, and M. Kreyscher, On the improvement of sea-ice models for climate simulations: the sea ice model intercomparison project. Ann. Glaciology, 25, 183-187, 1997.

Parkinson, C.L., D.J. Cavalieri, P. Gloersen, H.J. Zwally, and J.C. Comiso, Spatial distribution of trends and seasonality in the hemispheric sea ice covers: 1978-1996. J. Geophys. Res., $104(\mathrm{C9}), 20,827-20,835,1999$.

Rothrock, D.A., Y. YU, and G.A. Maykut, Thinning of Arctic sea-ice cover. Geophys. Res. Lett., 26(23), 3469-3472, 1999.

Serreze, A.J., J.E. Walsh, F.S. Chapin, T. Osterkamp, M. Dyurgerov, V. Romanovsky, W.C. Oechel, J. Morison, T. Zhang, and R.G. Barry, Observational evidence of recent change in the northern high-latitude environment. Climatic Change, 46, 159-207, 2000.

Semtner, A.J., A model for the thermodynamic growth of sea ice in numerical investigations of climate. J. Phys. Oceanogr., 6, 379-389, 1976.

Smith, D.M., Recent increase in the length of the melt season of perennial Arctic sea ice. Geophys. Res. Lett., 25(5), 655-658, 1998.

von Storch, H. and F.W. Zwiers, Statistıcal Analysıs in Climate Research. Cambridge University Press. ISBN 0-521-45071-3, 1999.

Walsh, J.E., W.L. Chapman, and T.L. Shy, Recent decrease of sea level pressure in the central Arctic. J. Climate, 9, 480-486, 1996.

M. Hilmer and P. Lemke, Institut für Meereskunde an der Universität Kiel, Düsternbrooker Weg 20, D-24105 Kiel, Germany (e-mail: mhilmer@ifm.uni-kiel.de; plemke@ifm.uni-kiel.de)

(Received January 1, 2000; accepted September 1, 2000.) 